\title{
Noninvasive follicular thyroid neoplasm with papillary-like nuclear features (NIFTP): a review for clinicians
}

\author{
Pedro Weslley Rosario and Gabriela Franco Mourão \\ Santa Casa de Belo Horizonte, Minas Gerais, Brazil \\ Correspondence should be addressed to P W Rosario: pedrowsrosario@gmail.com
}

\begin{abstract}
Noninvasive follicular thyroid neoplasm with papillary-like nuclear features (NIFTP) is an encapsulated or clearly delimited, noninvasive neoplasm with a follicular growth pattern and nuclear features of papillary thyroid carcinoma (PTC). It is considered a 'premalignant' lesion of the RAS-like group. Ultrasonography (US), cytology and molecular tests are useful to suspect thyroid nodules that correspond to NIFTP but there is wide overlap of the results with the encapsulated follicular variant of PTC (E-FVPTC). In these nodules that possibly or likely correspond to NIFTP, if surgery is indicated, lobectomy is favored over total thyroidectomy. The diagnosis of NIFTP is made after complete resection of the lesion by observing well-defined criteria. In the case of patients who received the diagnosis of FVPTC and whose pathology report does not show findings of malignancy (lymph node metastasis, extrathyroidal invasion, vascular/capsular invasion), if the tumor was encapsulated or well delimited, the slides can be revised by an experienced pathologist to determine whether the diagnostic criteria of NIFTP are met, but special attention must be paid to the adequate representativeness of the capsule and tumor. Since NIFTP is not 'malignant', tumor staging is not necessary and patients are not submitted to thyroid cancer protocols or guidelines. We believe that patients with NIFTP without associated malignancy and without nodules detected by US of the remnant lobe (if submitted to lobectomy) can be managed like those with follicular adenoma.
\end{abstract}

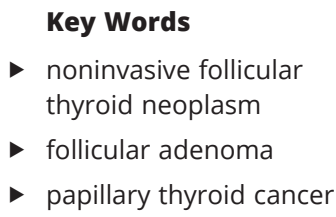

Endocrine-Related Cancer (2019) 26, R259-R266

\section{Definition}

Noninvasive follicular thyroid neoplasm with papillarylike nuclear features (NIFTP) is an encapsulated or clearly delimited, noninvasive neoplasm with a follicular growth pattern and nuclear features of papillary thyroid carcinoma (PTC), but without well-formed papillae or psammoma bodies and without typical findings of the aggressive subtypes of PTC or poorly differentiated carcinoma (Nikiforov et al. 2016, 2018, Lloyd et al. 2017). It is considered a 'borderline' or 'pre-malignant' lesion (Lloyd et al. 2017).

\section{The change from the noninvasive encapsulated follicular variant of PTC (E-FVPTC) to NIFTP}

When Nikiforov et al. (2016) proposed the term NIFTP, it was already known that encapsulated/well-delimited tumors of FVPTC without vascular/capsular invasion had an excellent prognosis after complete resection, even when treated only with lobectomy (Liu et al. 2006, Rivera et al. 2010, Rosario et al. 2014, Ganly et al. 2015). In the largest series published so far (Rosario et al. 2014), we reported no case of recurrence after 1-10 years (median 7 years) 
of follow-up among 108 patients with this tumor, all of them $>1 \mathrm{~cm}$. None of the patients received radioiodine or TSH suppression and 57 were treated with lobectomy. Some guidelines already recommended more conservative treatment for this histological subtype (Perros et al. 2014, Haugen et al. 2016).

Nevertheless, that publication (Nikiforov et al. 2016) had a strong impact in clinical practice. First, the absence of metastases in 109 patients with tumors $>1 \mathrm{~cm}$ treated without radioiodine and followed up for at least 10 years reported in the multicenter study (Nikiforov et al. 2016) reinforced the excellent prognosis of this neoplasm after its complete resection. Second, removal of the term 'cancer' itself probably (i) reduces the negative psychological impact on the patient and relatives; (ii) increases the physician's safety to opt for conservative treatment and less intense follow-up and (iii) increases patient acceptance of less aggressive therapy and less frequent follow-up. Third, clear diagnostic criteria were established since variations existed in the definition of E-FVPTC. Indeed, this attempt to standardize the diagnostic criteria, in which pathologists from several countries participated, was an important contribution. Until then, different definitions, especially of the nuclear alterations sufficient to characterize PTC, resulted in a significant interobserver variation in the final diagnosis of follicular thyroid neoplasms. A detailed review of this aspect was recently published in this journal (Amendoeira et al. 2018). Fourth and probably the most important, in addition to the name change from noninvasive E-FVPTC to NIFTP, the nature of the lesion was altered, which was no longer classified as 'malignant'. This proposal was subsequently endorsed by the World Health Organization (WHO) in the 4th edition of the classification of endocrine tumors (Lloyd et al. 2017).

Since NIFTP is not 'cancer', tumor staging (e.g., TNM/AJCC) is not necessary and patients with this diagnosis do not need to be submitted to protocols or guidelines for differentiated thyroid carcinoma. Compared to data that include it as 'malignant' tumor, with NIFPT no longer being considered 'cancer', a reduction in the risk of 'malignancy' is observed in thyroid nodules with the features shown in Table 1, which are more frequently found in lesions corresponding to NIFTP. This fact has possible implications for the predictive value for 'malignancy' of ultrasonography (US) (Chaigneau et al. 2018, Rosario et al. 2018a,b), cytology (Cibas \& Ali 2017, Rocha et al. 2018), molecular tests (Sahli et al. 2017) and fluorodeoxyglucose positron emission tomography (FDG-PET) (Rosario et al. 2019). Tumors that nowadays correspond to NIFTP were included in the group of low-risk PTC (Wong et al. 2017, Rosario 2019a), that is, tumors restricted to the thyroid without vascular invasion or typical components of aggressive subtypes, in the absence of the BRAFV600E mutation (Haugen et al. 2016). Thus, a slight increase in the recurrence rate may occur after the exclusion of NIFTP from this group. Clearly, all these impacts depend on the prevalence of NIFTP in the population studied and the diagnosis of NIFTP is less often made in Asian populations (Bychkov et al. 2018).

\section{Preoperative suspicion of NIFTP}

Although the preoperative diagnosis is not possible, knowledge of thyroid nodules that possibly or likely correspond to NIFTP is important. In these nodules, if surgery is indicated, lobectomy is recommended, except if the choice for total thyroidectomy were due to reasons other than the risk of malignancy of the nodule or to concern about another nodule.

Ultrasonography (Hahn et al. 2017, Rosario 2017a, Yang et al. 2017), cytology (Rosario 2017a, Bongiovanni et al. 2018) and molecular tests (Nikiforov 2017) are useful for suspecting NIFTP. Some results render NIFTP unlikely (Table 1 ) and are more characteristics of classical

Table 1 Data that lead to the reasonable possibility of a thyroid nodule corresponding to NIFTP.

\begin{abstract}
Clinical examination Ultrasonography
\end{abstract}

Fine-needle aspiration
Absence of clinically apparent or known metastasis of thyroid origina

Absence of LNMa

Nodule without the following findings: extrathyroidal extension, microcalcification, taller-than-wide shape, spiculate/microlobulate/ill-defined margin, high suspicion of malignancy Category III, IV or V cytology of the Bethesda system ${ }^{\mathrm{b}}$ Nodule without mutations or with RAS or other RAS-like mutations (e.g., PAX8/PPARG rearrangement)c

aThe presence excludes NIFTP or indicates associated thyroid malignancy; bfollicular pattern, no papillae, no psammomatous calcifications, no florid nuclear features of papillary thyroid carcinoma, no necrosis or mitoses; CNIFTP is virtually excluded in the case of a nodule with BRAFV600E or other BRAFV600E-like mutations (e.g., RET/PTC fusions), or high-risk mutations (e.g., TERT promoter, p53).

(c) 2019 Society for Endocrinology Published by Bioscientifica Ltd. Printed in Great Britain 
PTC, infiltrative FV and aggressive subtypes. In contrast, these tumors less frequently exhibit the typical findings of nodules that correspond to NIFTP (Table 1). However, the findings of NIFTP and E-FVPTC, especially with lower invasion, widely overlap. The Doppler vascularization pattern (Hahn et al. 2017, Yang et al. 2017, Rosario 2018b), histogram analysis of greyscale sonograms (Kwon et al. 2018) and uptake of FDG on PET (Rosario 2018d) have been studied but do also not distinguish NIFTP from E-FVPTC.

\section{Diagnosis of NIFTP}

At present, the diagnosis of NIFTP can only be made after complete resection of the lesion observing the following criteria (Nikiforov et al. 2016, 2018, Lloyd et al. 2017): (i) encapsulation or clear demarcation from adjacent thyroid parenchyma; (ii) follicular growth pattern with no well-formed papillae, no psammoma bodies and $<30 \%$ solid/trabecular/insular growth pattern; (iii) nuclear features of PTC (nuclear score 2-3); (iv) no vascular or capsular invasion; (v) no tumor necrosis or high mitotic activity. Molecular tests are helpful but not required for NIFTP diagnosis. When obtained, BRAFV600E or other $B R A F V 600 E$-like mutations (e.g., RET/PTC fusions) or high-risk mutations (e.g., TERT promoter, $p 53$ ) are absent in NIFTP (Nikiforov et al. 2018). The initial criteria (Nikiforov et al. 2016) were revised in 2018 (Nikiforov et al. 2018). In the presence of true well-formed papillae, even if accounting for $<1 \%$ of the tumor, the latter is no longer considered NIFTP (Nikiforov et al. 2018). Tumors with papillae have been associated with a non-negligible frequency of the V600E mutation in the BRAF gene (Cho et al. 2017, Kim et al. 2018b,c, Rosario 2019b), lymph node metastases (Cho et al. 2017, Kim et al. 2018c, Rosario $2019 b$ ), and even a case of distant metastasis (Cho et al. 2017). If exuberant nuclear alterations of PTC (score 3) are present, comprehensive revision of the entire tumor capsule interface is recommended in order to identify invasion and of the entire tumor in order to identify structural components of PTC (Nikiforov et al. 2018).

When morphological criteria are strictly observed, the finding of the BRAFV600E mutation in NIFTP is very unlikely and most studies show its absence (Nikiforov et al. 2016, Johnson \& Sadow 2018, Johnson et al. 2018, Jung et al. 2018, Kim et al. 2018a). We reviewed studies that reported exceptional cases of NIFTP with the BRAFV600E mutation. Cho et al. (2017) and Kim et al. (2018b) found this mutation in $10 / 105$ and $3 / 43$ cases, respectively, but all 13 tumors had papillae. Lee et al. (2017) reported the mutation in $5 / 24$ cases. When four of these five cases were revised, papillae were found in one case, capsular invasion in another and inadequate representativeness of the tumor in the other two (Kakudo et al. 2018). In the series of Kim et al. (2018c), 9/73 NIFTP carried the mutation: four tumors with well-formed papillae, four with abortive papillae and one result was false-positive because of adjacent BRAF-positive PTC. Zhao et al. (2017) found 1/48 NIFTPs with the BRAFV600E mutation, but the authors recognize that the lack of examination of the entire tumor may have failed to detect the components of classical PTC.

Despite the small number of reported cases, the diagnosis of NIFTP also applies to children and adolescents and the absence of metastases has been demonstrated in this age group (Chereau et al. 2019, Rosario \& Mourão 2018).

The size of the tumor does not constitute a criterion for the diagnosis of NIFTP (Nikiforov et al. 2018), although some cases require greater care and time-consuming evaluation to ensure the absence of excluding findings. Reviewing 250 patients with subcentimeter NIFTP from nine studies (Thompson 2016, Can et al. 2017, Hahn et al. 2017, Kwon et al. 2017, Johnson \& Sadow 2018, Mainthia et al. 2018, Rosario 2018c, Shafique et al. 2018, Xu et al. 2018), without associated PTC, we found only two patients with micrometastases $<2 \mathrm{~mm}$ in a single lymph node in the central compartment, none with distant metastases and no case of recurrence. In addition, reviewing 265 patients with NIFTP $\geq 4 \mathrm{~cm}$ (Thompson 2016, Golding et al. 2017, Kwon et al. 2017, Rosario 2017b, Xu et al. 2017a, Chereau et al. 2019, Kim et al. 2018b, Mainthia et al. 2018, Parente et al. 2018), excluding cases with associated PTC, we did not identify any patients with lymph node metastases (LNM), only one with pulmonary metastases and no case of recurrence.

Although there is no consensus, we believe that tumors composed of cells with oncocytic (Hürthle cells) appearance can be classified as NIFTP if they meet all other diagnostic criteria ( $\mathrm{Xu}$ et al. 2019). We report here the evolution of ten patients with NIFTP with oncocytic features seen at our institution. There were eight women and two men ranging in age from 18 to 72 years. Median tumor size was $2.2 \mathrm{~cm}$ (range, $1.1-3.5 \mathrm{~cm}$ ). Six patients were submitted to total thyroidectomy and four to lobectomy. No LNM were detected at diagnosis. Complete resection of the primary tumor was achieved in all patients. Radioiodine was not administered to any of the ten patients. The patients were followed up for 
18-144 months (median 72 months). None of the patients developed structural disease or biochemical recurrence during follow-up.

\section{Outcomes in studies involving patients with NIFTP}

Since a greater representativeness (capsule and tumor) than usually obtained in the past is currently required for the diagnosis of NIFTP, we do not believe that the frequency of 'outcomes' (i.e., metastases on presentation and recurrences) reported in retrospective studies is underestimated (Rosario \& Mourão 2019). On the contrary, it is possible that they diagnosed retrospectively as NIFTP tumors that were PTC; with the current requirement, even better results (in terms of 'outcomes') are expected (Rosario \& Mourão 2019).

Reviewing studies published since the pioneering article (Nikiforov et al. 2016) until December 2018 and excluding patients with known associated PTC or tumors with well-formed papillae (in $<1 \%$ of the tumor) that are no longer diagnosed as NIFTP (Nikiforov et al. 2018), we found no report of death due to NIFTP and only one case of pulmonary metastasis (Parente et al. 2018). However, LNM were reported (Jiang et al. 2016, Cho et al. 2017, Hahn et al. 2017, Kwon et al. 2017, Kim et al. 2018b,c, Parente et al. 2018, You et al. 2018). Evaluation of these last cases showed that (i) involvement was restricted to the central compartment (N1a) in all patients, (ii) all but one patient had a single lymph node affected, (iii) all but one study reported the size of LNM and all were microscopic $(<2 \mathrm{~mm})$ and (iv) no recurrence was reported.
Table 2 lists the studies involving the largest number of patients with NIFTP that reported 'outcomes'.

The presence of metastases in patients with NIFTP does not necessarily confirm its potential of dissemination. First, insufficient representativeness of the tumor and capsule that fails to detect findings excluding NIFTP cannot be ruled out in some retrospective studies. Second, the capacity of minute microcarcinomas $(<3 \mathrm{~mm})$ to metastasize to lymph nodes (Wada et al. 2003) and even to distant organs (Xu et al. 2017b) is known. Many patients with NIFTP could have these minute microcarcinomas that were not detected by US of the remnant lobe (in patients submitted to lobectomy) or that escaped the slides obtained from the tumor. Another possibility would be regression of the microcarcinoma after it metastasized. The report of dissociation between LNM with mutation in the $B R A F$ gene and the primary tumor (NIFTP) negative for this mutation supports the hypothesis of another, although not apparent, metastasis origin (Kim et al. $2018 b)$.

\section{Management after resection}

In patients with NIFTP, after its complete resection and in the absence of associated malignancy (including microcarcinoma), the need for and protocol of follow-up are matters of debate. There seems to be consensus that suppression of TSH is not necessary. According to the American Thyroid Association, complementary tests (thyroglobulin (Tg), antithyroglobulin antibodies (TgAb), neck US) are not mandatory (Haugen et al. 2016), while some authors recommend NIFTP to be monitored in the

Table 2 Outcomes (metastases on presentation or recurrences) observed in studies involving the largest number of patients with NIFTP.

\begin{tabular}{lcc}
\hline Reference & & Number of patients \\
\cline { 1 - 1 } Thompsom (2016) & 77 \\
Nikiforov et al. (2016) & 109 \\
Rosario et al. (2016) & 129 \\
Xu et al. (2017a) & 79 \\
Kwon et al. (2017) & 105 \\
Cho et al. (2017) & 95 \\
Parente et al. (2018) & 102 \\
Mainthia et al. (2018) & 164 \\
Johnson and Sadow (2018) & 130 \\
Chereau et al. (2019) & 363 \\
Kim et al. (2018c) & 73 \\
\hline
\end{tabular}

\begin{tabular}{l}
\hline Length of follow-up \\
\hline $1.2-12.5$ years (median 11.8) \\
10-26 years (median 13) \\
12-146 months (median 72) \\
$0.3-26$ years (median 5.8) \\
- \\
17-96 months (median 36) \\
0-11 years (mean 5.7) \\
IQR 12-49 months (median 24) \\
Mean 1.63 years \\
IQR $12-146$ months (median 55) \\
0.6-31.9 months (mean 15.5) \\
\hline
\end{tabular}

\begin{tabular}{c}
\hline LNM $^{*}$ \\
\hline 0 \\
0 \\
0 \\
0 \\
2 \\
2 \\
5 \\
0 \\
0 \\
0 \\
2 \\
\hline
\end{tabular}

Distant metastasis*

*Diagnosed on presentation or during follow-up in patients with NIFTP according to the current criterion and without associated carcinoma. IQR interquartile range; LNM, lymph node metastases. 
same way as low-risk PTC (Cho et al. 2017, Parente et al. 2018)

After the name change removing the term 'cancer' (Nikiforov et al. 2016), alteration of the nature of the lesion which is no longer 'malignant' (Lloyd et al. 2017), and definition of somehow strict diagnostic criteria designed exactly to rule out the possibility of metastases (Nikiforov et al. 2018), maintaining patients with NIFTP under a similar follow-up as patients with PTC seems to be little justified (Rosario \& Mourão 2019). In our view (Rosario 2018a, Rosario \& Mourão 2019), if patients with NIFTP continue to be followed up like those with lowrisk PTC, the practical impact promoted by these changes would have been minimal or none since noninvasive E-FVPTC was known to have an excellent prognosis after lobectomy (Liu et al. 2006, Rivera et al. 2010, Rosario et al. 2014, Ganly et al. 2015) and conservative treatment of this histological subtype was already recommended by the available guidelines (Perros et al. 2014, Haugen et al. 2016).

It is expected that specific protocols or recommendations for selective follow-up of subgroups of patients with NIFTP will be proposed, but they will be empirical and based on the extrapolation of data from patients with 'cancer'. Finally, because of the exceptionality of 'outcomes', performing follow-up similar to that of low-risk PTC to detect an 'eventual' recurrence of NIFTP would require hundreds of tests of $\mathrm{Tg}, \mathrm{TgAb}$ and US at the end of 10 years, with probably unviable costs and numerous false-positive results and their potential consequences (Rosario et al. 2018c).

We believe that patients with NIFTP without associated malignancy and without nodules detected by US of the remnant lobe (if submitted to lobectomy) can be managed like those with follicular adenoma. This management seems to be more harmonic with the current nomenclature (not containing the term 'cancer') and the nature of the lesion (not 'malignant') and is based on (i) the existence of well-defined diagnostic criteria, (ii) molecular signature, (iii) rarity of metastases on presentation, a finding that can even be a coincidence and (iv) the virtual absence of recurrences. These last aspects have been demonstrated in the past for noninvasive E-FVPTC and now using the criteria of NIFTP.

\section{Revision of histology slides}

Patients who were diagnosed in the past with FVPTC and whose pathology report did not show findings of malignancy (LNM, extrathyroidal invasion, vascular/ capsular invasion) can have their slides revised by an experienced pathologist if the tumor is encapsulated or well delimited (non-infiltrative) in order to determine whether the diagnostic criteria of NIFTP are met. In this reassessment, special attention must be paid to the adequate representativeness of the capsule and tumor and establishment of the diagnosis of NIFTP is not recommended if it is insufficient unless more sections can be submitted. The diagnosis of NIFTP cannot be based on retrospective interpretation of the original pathology report, especially when this report was obtained before definition of the current diagnostic criteria.

Despite its inclusion in the WHO classification of endocrine tumors (Lloyd et al. 2017), it may still take some time until the NIFTP nomenclature becomes routine in all pathology laboratories. During this period of transition, we recommend revision by pathologist in the case of a diagnosis of noninvasive E-FVPTC or FVPTC with the characteristics cited above (neoplasm with capsule or clear delimitation without LNM, extrathyroidal invasion, capsular/vascular invasion) to determine whether the tumor meets the criteria for NIFTP.

In the above situations, molecular tests can be requested if available and feasible, but they do not substitute histology.

\section{Conclusion}

Clinicians must be aware of the ultrasonographic, cytological and molecular findings of nodules corresponding to NIFTP since this knowledge influences the definition of the extent of surgery, if indicated, favoring lobectomy. In addition, clinicians and pathologists must be familiar with the histological criteria for the diagnosis of NIFTP to spare patients with this tumor (without associated malignancy) from additional treatment and from the traditional follow-up recommended for differentiated thyroid cancer.

Declaration of interest

The authors declare that there is no conflict of interest that could be perceived as prejudicing the impartiality of this review.

\section{Funding}

This research did not receive any specific grant from any funding agency in the public, commercial or not-for-profit sector. (c) 2019 Society for Endocrinology Published by Bioscientifica Ltd. Printed in Great Britain 


\section{Author contribution statement}

Study design: All authors. Study conduct: All authors. Data management: All authors. Data analysis: All authors. Data interpretation: All authors. Manuscript writing: All authors. Manuscript review and approval: All authors.

\section{References}

Amendoeira I, Maia T \& Sobrinho-Simões M 2018 Non-invasive follicular thyroid neoplasm with papillary-like nuclear features (NIFTP): impact on the reclassification of thyroid nodules. EndocrineRelated Cancer 25 R247-R258. (https://doi.org/10.1530/ERC-17-0513)

Bongiovanni M, Giovanella L, Romanelli F \& Trimboli P 2018 Cytological diagnoses associated with non-invasive follicular thyroid neoplasms with papillary-like nuclear features, (NIFTP) according to the Bethesda system for reporting thyroid cytopathology: a systematic review and meta-analysis. Thyroid 29 222-228. (https:// doi.org/10.1089/thy.2018.0394)

Bychkov A, Jung CK, Liu Z \& Kakudo K 2018 Noninvasive follicular thyroid neoplasm with papillary-like nuclear features in Asian practice: perspectives for surgical pathology and cytopathology. Endocrine Pathology 29 276-288. (https://doi.org/10.1007/s12022-0189519-6)

Can N, Celik M, Sezer YA, Ozyilmaz F, Ayturk S, Tastekin E, Sut N, Gurkan H, Ustun F, Bulbul BY, et al. 2017 Follicular morphological characteristics may be associated with invasion in follicular thyroid neoplasms with papillary-like nuclear features. Bosnian Journal of Basic Medical Sciences 17 211-220. (https://doi.org/10.17305/ bjbms.2017.2039)

Chaigneau E, Russ G, Royer B, Bigorgne C, Bienvenu-Perrard M, Rouxel A, Leenhardt L, Belin L \& Buffet C 2018 TIRADS score is of limited clinical value for risk stratification of indeterminate cytological results. European Journal of Endocrinology 179 13-20. (https://doi.org/10.1530/EJE-18-0078)

Chereau N, Greilsamer T, Mirallié E, Sadowski SM, Pusztaszeri M, Triponez F, Baud G, Pattou F, Christou N, Mathonnet M, et al. 2019 NIFT-P: are they indolent tumors? Results of a multi-institutional study. Surgery 165 12-16. (https://doi.org/10.1016/j. surg.2018.04.089)

Cho U, Mete O, Kim MH, Bae JS \& Jung CK 2017 Molecular correlates and rate of lymph node metastasis of non-invasive follicular thyroid neoplasm with papillary-like nuclear features and invasive follicular variant papillary thyroid carcinoma: the impact of rigid criteria to distinguish non-invasive follicular thyroid neoplasm with papillarylike nuclear features. Modern Pathology 30 810-825. (https://doi. org/10.1038/modpathol.2017.9)

Cibas ES \& Ali SZ 2017 The 2017 Bethesda system for reporting thyroid cytopathology. Thyroid 27 1341-1346. (https://doi.org/10.1089/ thy.2017.0500)

Ganly I, Wang L, Tuttle RM, Katabi N, Ceballos GA, Harach HR \& Ghossein R 2015 Invasion rather than nuclear features correlates with outcome in encapsulated follicular tumors: further evidence for the reclassification of the encapsulated papillary thyroid carcinoma follicular variant. Human Pathology 46 657-664. (https://doi. org/10.1016/j.humpath.2015.01.010)

Golding A, Shively D, Bimston DN \& Harrell RM 2017 Noninvasive encapsulated follicular variant of papillary thyroid cancer: clinical lessons from a community-based endocrine surgical practice. International Journal of Surgical Oncology 2017 4689465. (https://doi. org/10.1155/2017/4689465)

Hahn SY, Shin JH, Oh YL, Kim TH, Lim Y \& Choi JS 2017 Role of ultrasound in predicting tumor invasiveness in follicular variant of papillary thyroid carcinoma. Thyroid 27 1177-1184. (https://doi. org/10.1089/thy.2016.0677)

Haugen BR, Alexander EK, Bible KC, Doherty GM, Mandel SJ, Nikiforov YE, Pacini F, Randolph GW, Sawka AM \& Schlumberger M 20162015 American Thyroid Association management guidelines for adult patients with thyroid nodules and differentiated thyroid cancer: the American Thyroid Association guidelines task force on thyroid nodules and differentiated thyroid cancer. Thyroid 26 1-133. (https://doi.org/10.1089/thy.2015.002)

Jiang XS, Harrison GP \& Datto MB 2016 Young investigator challenge: molecular testing in noninvasive follicular thyroid neoplasm with papillary-like nuclear features. Cancer Cytopathology 124 893-900. (https://doi.org/10.1002/cncy.21802)

Johnson DN \& Sadow PM 2018 Exploration of BRAFV600E as a diagnostic adjuvant in the non-invasive follicular thyroid neoplasm with papillary-like nuclear features (NIFTP). Human Pathology 82 32-38. (https://doi.org/10.1016/j.humpath.2018.06.033)

Johnson DN, Furtado LV, Long BC, Zhen CJ, Wurst M, Mujacic I, Kadri S, Segal JP, Antic T \& Cipriani NA 2018 Noninvasive follicular thyroid neoplasms with papillary-like nuclear features are genetically and biologically similar to adenomatous nodules and distinct from papillary thyroid carcinomas with extensive follicular growth. Archives of Pathology and Laboratory Medicine 142 838-850. (https:// doi.org/10.5858/arpa.2017-0118-OA)

Jung CK, Kim Y, Jeon S, Jo K, Lee S \& Bae JS 2018 Clinical utility of EZH1 mutations in the diagnosis of follicular-patterned thyroid tumors. Human Pathology 81 9-17. (https://doi.org/10.1016/j. humpath.2018.04.018)

Kakudo K, El-Naggar AK, Hodak SP, Khanafshar E, Nikiforov YE, Nosé V \& Thompson LDR 2018 Noninvasive follicular thyroid neoplasm with papillary-like nuclear features (NIFTP) in thyroid tumor classification. Pathology International 68 327-333. (https://doi. org/10.1111/pin.12673)

Kim M, Jeon MJ, Oh HS, Park S, Kim TY, Shong YK, Kim WB, Kim K, Kim WG \& Song DE 2018a BRAF and RAS mutational status in noninvasive follicular thyroid neoplasm with papillary-like nuclear features and invasive subtype of encapsulated follicular variant of papillary thyroid carcinoma in Korea. Thyroid 28 504-510. (https:// doi.org/10.1089/thy.2017.0382)

Kim MJ, Won JK, Jung KC, Kim JH, Cho SW, Park DJ \& Park YJ $2018 b$ Clinical characteristics of subtypes of follicular variant papillary thyroid carcinoma. Thyroid 28 311-318. (https://doi.org/10.1089/ thy.2016.0671)

Kim TH, Lee M, Kwon AY, Choe JH, Kim JH, Kim JS, Hahn SY, Shin JH, Chung MK, Son YI, et al. 2018c Molecular genotyping of the noninvasive encapsulated follicular variant of papillary thyroid carcinoma. Histopathology 72 648-661. (https://doi.org/10.1111/ his.13401)

Kwon H, Jeon MJ, Yoon JH, Hong SJ, Lee JH, Kim TY, Shong YK, Kim WB, Kim WG \& Song DE 2017 Preoperative clinicopathological characteristics of patients with solitary encapsulated follicular variants of papillary thyroid carcinomas. Journal of Surgical Oncology 116 746-755. (https://doi.org/10.1002/jso.24700)

Kwon MR, Shin JH, Hahn SY, Oh YL, Kwak JY, Lee E \& Lim Y 2018 Histogram analysis of greyscale sonograms to differentiate between the subtypes of follicular variant of papillary thyroid cancer. Clinical Radiology 73 591.e1-591.e7. (https://doi.org/10.1016/j. crad.2017.12.008)

Lee SE, Hwang TS, Choi YL, Kim WY, Han HS, Lim SD, Kim WS, Yoo YB \& Kim SK 2017 Molecular profiling of papillary thyroid carcinoma in Korea with a high prevalence of BRAFV600E mutation. Thyroid $\mathbf{2 7}$ 802-810. (https://doi.org/10.1089/thy.2016.0547)

Liu J, Singh B, Tallini G, Carlson DL, Katabi N, Shaha A, Tuttle RM \& Ghossein RA 2006 Follicular variant of papillary thyroid carcinoma: a clinicopathologic study of a problematic entity. Cancer 107 1255-1264. (https://doi.org/10.1002/cncr.22138) https://erc.bioscientifica.com

https://doi.org/10.1530/ERC-19-0048 (c) 2019 Society for Endocrinology Published by Bioscientifica Ltd. Printed in Great Britain 
Lloyd RV, Osamura RY, Klöppel G \& Rosai J 2017 WHO Classification of Tumours of Endocrine Origins, 4th ed. Lyon, France: International Agency for Research on Cancer.

Mainthia R, Wachtel H, Chen Y, Mort E, Parangi S, Sadow PM \& Lubitz CC 2018 Evaluating the projected surgical impact of reclassifying noninvasive encapsulated follicular variant of papillary thyroid cancer as noninvasive follicular thyroid neoplasm with papillary-like nuclear features. Surgery 163 60-65. (https://doi. org/10.1016/j.surg.2017.04.037)

Nikiforov YE 2017 Role of molecular markers in thyroid nodule management: then and now. Endocrine Practice 23 979-988. (https:// doi.org/10.4158/EP171805.RA)

Nikiforov YE, Seethala RR, Tallini G, Baloch ZW, Basolo F, Thompson LD, Barletta JA, Wenig BM, Al Ghuzlan A, Kakudo K, et al. 2016 Nomenclature revision for encapsulated follicular variant of papillary thyroid carcinoma: a paradigm shift to reduce overtreatment of indolent tumors. JAMA Oncology 2 1023-1029. (https://doi.org/10.1001/jamaoncol.2016.0386)

Nikiforov YE, Baloch ZW, Hodak SP, Giordano TJ, Lloyd RV, Seethala RR \& Wenig BM 2018 Change in diagnostic criteria for noninvasive follicular thyroid neoplasm with papillarylike nuclear features. JAMA Oncology 4 1125-1126. (https://doi.org/10.1001/ jamaoncol.2018.1446)

Parente DN, Kluijfhout WP, Bongers PJ, Verzijl R, Devon KM, Rotstein LE, Goldstein DP, Asa SL, Mete O \& Pasternak JD 2018 Clinical safety of renaming encapsulated follicular variant of papillary thyroid carcinoma: is NIFTP truly benign? World Journal of Surgery 42 321-326. (https://doi.org/10.1007/s00268-017-4182-5)

Perros P, Boelaert K, Colley S, Evans C, Evans RM, Gerrard Ba G, Gilbert J, Harrison B, Johnson SJ, Giles TE, et al. 2014 Guidelines for the management of thyroid cancer. Clinical Endocrinology $\mathbf{8 1}$ (Supplement 1) 1-122. (https://doi.org/10.1111/cen.12515)

Rivera M, Ricarte-Filho J, Knauf J, Shaha A, Tuttle M, Fagin JA \& Ghossein RA 2010 Molecular genotyping of papillary thyroid carcinoma follicular variant according to its histological subtypes (encapsulated vs infiltrative) reveals distinct BRAF and RAS mutation patterns. Modern Pathology 23 1191-1200. (https://doi.org/10.1038/ modpathol.2010.112)

Rocha TG, Rosario PW, Silva AL, Nunes MB, Silva TH, de Oliveira PHL \& Calsolari MR 2018 Ultrasonography classification of the American Thyroid Association for predicting malignancy in thyroid nodules $>1 \mathrm{~cm}$ with indeterminate cytology: a prospective study. Hormone and Metabolic Research 50 597-601. (https://doi.org/10.1055/a-0655-3016)

Rosario PW 2017a Ultrasonography and cytology as predictors of noninvasive follicular thyroid (NIFTP) neoplasm with papillary-like nuclear features: importance of the differential diagnosis with the invasive encapsulated follicular variant of papillary thyroid cancer Clinical Endocrinology 87 635-636. (https://doi.org/10.1111/ cen.13317)

Rosario PW 2017b Long-term outcomes of patients with noninvasive follicular thyroid neoplasm with papillary-like nuclear features (NIFTP) $\geq 4 \mathrm{~cm}$ treated without radioactive iodine. Endocrine Pathology 28 367-368. (https://doi.org/10.1007/s12022-017-9493-4)

Rosario PW 2018a Is Doppler ultrasonography of value for the differentiation between noninvasive follicular thyroidneoplasm with papillary-like nuclear features (NIFTP) and invasive encapsulated follicular variant of papillary thyroid carcinoma? Clinical Endocrinology 88 506-507. (https://doi.org/10.1111/cen.13523)

Rosario PW $2018 b$ Glucose uptake evaluated by $18 \mathrm{~F}$-fluorodeoxyglucose positron emission tomography in noninvasive follicular thyroid neoplasm with papillary-like nuclear features. Diagnostic Cytopathology 46 456-457. (https://doi.org/10.1002/dc.23913)

Rosario PW 2018c Subcentimetre non-invasive follicular thyroid neoplasm with papillary-like nuclear features (NIFTP). Histopathology 73 535-537. (https://doi.org/10.1111/his.13660)
Rosario PW 2018d Noninvasive follicular thyroid neoplasm with papillary-like nuclear features (NIFTP): did we trade six for a half a dozen? World Journal of Surgery 42 2277-2278. (https://doi. org/10.1007/s00268-017-4351-6)

Rosario PW 2019a Impact of noninvasive follicular thyroid neoplasm with papillary-like nuclear features (NIFTP) on the outcomes of lobectomy. Annals of Surgical Oncology 26 306. (https://doi. org/10.1245/s10434-018-6947-y)

Rosario PW 2019b Diagnostic criterion of noninvasive follicular thyroid neoplasm with papillary-like nuclear features (NIFTP): absence of papillae. Human Pathology 83 225. (https://doi.org/10.1016/j. humpath.2018.05.029)

Rosario PW \& Mourão GF 2018 Noninvasive follicular thyroid neoplasm with papillary-like nuclear features (NIFTP) in children and adolescents. Endocrine 61 542-544. (https://doi.org/10.1007/s12020018-1667-4)

Rosario PW \& Mourão GF 2019 Follow-up of noninvasive follicular thyroid neoplasm with papillary-like nuclear features (NIFTP). Head and Neck 41 833-834. (https://doi.org/10.1002/hed.25550)

Rosario PW, Penna GC \& Calsolari MR 2014 Noninvasive encapsulated follicular variant of papillary thyroid carcinoma: is lobectomy sufficient for tumours $\geq 1 \mathrm{~cm}$ ? Clinical Endocrinology 81 630-632. (https://doi.org/10.1111/cen.12387)

Rosario PW, Mourão GF, Nunes MB, Nunes MS \& Calsolari MR 2016 Noninvasive follicular thyroid neoplasm with papillary-like nuclear features. Endocrine-Related Cancer 23 893-897. (https://doi. org/10.1530/ERC-16-0379)

Rosario PW, da Silva AL, Nunes MB \& Borges MAR 2018a Risk of malignancy in thyroid nodules using the American College of Radiology thyroid imaging reporting and data system in the NIFTP era. Hormone and Metabolic Research 50 735-737. (https://doi. org/10.1055/a-0743-7326)

Rosario PW, Mourão GF, Oliveira LFF \& Calsolari MR 2018b Long-term follow-up in patients with noninvasive follicular thyroid neoplasm with papillary-like nuclear features (NIFTP) Without a suspicion of persistent disease in postoperative assessment. Hormone and Metabolic Research 50 223-226. (https://doi.org/10.1055/s-0043-121707)

Rosario PW, Silva TH \& de Oliveira PHL 2018c Impact of noninvasive follicular thyroid neoplasm with papillary-like nuclear features (NIFTP) on the risk of malignancy estimated by the ultrasonographic classification of the American Thyroid Association (ATA) in thyroid nodules $>1 \mathrm{~cm}$. Endocrine 60 535-536. (https://doi.org/10.1007/ s12020-018-1585-5)

Rosario PW, Rocha TG \& Calsolari MR 2019 Fluorine-18fluorodeoxyglucose positron emission tomography in thyroid nodules with indeterminate cytology: a prospective study. Nuclear Medicine Communications 40 185-187. (https://doi.org/10.1097/ MNM.0000000000000946)

Sahli ZT, Umbricht CB, Schneider EB \& Zeiger MA 2017 Thyroid nodule diagnostic markers in the face of the new NIFTP category: time for a reset? Thyroid 27 1393-1399. (https://doi.org/10.1089/thy.2017.0238)

Shafique K, LiVolsi VA, Montone K \& Baloch ZW 2018 Papillary thyroid microcarcinoma: reclassification to non-invasive follicular thyroid neoplasm with papillary-like nuclear features (NIFTP): a retrospective clinicopathologic study. Endocrine Pathology 29 339-345. (https://doi. org/10.1007/s12022-018-9546-3)

Thompson LD 2016 Ninety-four cases of encapsulated follicular variant of papillary thyroid carcinoma: a name change to noninvasive follicular thyroid neoplasm with papillary-like nuclear features would help prevent overtreatment. Modern Pathology 29 698-707. (https://doi.org/10.1038/modpathol.2016.65)

Wada N, Duh QY, Sugino K, Iwasaki H, Kameyama K, Mimura T, Ito K, Takami H \& Takanashi Y 2003 Lymph node metastasis from 259 papillary thyroid microcarcinomas: frequency, pattern of occurrence and recurrence, and optimal strategy for neck dissection. Annals of https://erc bioscientifica.com

https://doi.org/10.1530/ERC-19-0048 (c) 2019 Society for Endocrinology Published by Bioscientifica Ltd. Printed in Great Britain 
Surgery 237 399-407. (https://doi.org/10.1097/01. SLA.0000055273.58908.19)

Wong KS, Strickland KC, Angell TE, Nehs MA, Alexander EK, Cibas ES, Krane JF, Howitt BE \& Barletta JA 2017 The flip side of NIFTP: an increase in rates of unfavorable histologic parameters in the remainder of papillary thyroid carcinomas. Endocrine Pathology $\mathbf{2 8}$ 171-176. (https://doi.org/10.1007/s12022-017-9476-5)

Xu B, Tallini G, Scognamiglio T, Roman BR, Tuttle RM \& Ghossein RA $2017 a$ Outcome of large noninvasive follicular thyroid neoplasm with papillary-like nuclear features. Thyroid 27 512-517. (https://doi org/10.1089/thy.2016.0649)

Xu B, Tuttle RM, Sabra MM, Ganly I \& Ghossein R 2017b Primary thyroid carcinoma with low-risk histology and distant metastases: clinicopathologic and molecular characteristics. Thyroid 27 632-640. (https://doi.org/10.1089/thy.2016.0582)

Xu B, Farhat N, Barletta JA, Hung YP, Biase D, Casadei GP, Onenerk AM, Tuttle RM, Roman BR, Katabi N, et al. 2018 Should subcentimeter non-invasive encapsulated, follicular variant of papillary thyroid carcinoma be included in the noninvasive follicular thyroid neoplasm with papillary-like nuclear features category? Endocrine 59 143-150. (https://doi.org/10.1007/s12020-017-1484-1)
Xu B, Reznik E, Tuttle RM, Knauf J, Fagin JA, Katabi N, Dogan S, Aleynick N, Seshan V, Middha S, et al. 2019 Outcome and molecular characteristics of non-invasive encapsulated follicular variant of papillary thyroid carcinoma with oncocytic features. Endocrine [epub]. (https://doi.org/10.1007/s12020-019-01848-6)

Yang GCH, Fried KO \& Scognamiglio T 2017 Sonographic and cytologic differences of NIFTP from infiltrative or invasive encapsulated follicularvariant of papillary thyroid carcinoma: a review of 179 cases. Diagnostic Cytopathology 45 533-541. (https://doi.org/10.1002/ dc.23709)

You SH, Lee KE, Yoo RE, Choi HJ, Jung KC, Won JK, Kang KM, Yoon TJ, Choi SH, Sohn CH, et al. 2018 Prevention of total thyroidectomy in noninvasive follicular thyroid neoplasm with papillary-like nuclear features (NIFTP) based on combined interpretation of ultrasonographic and cytopathologic results. Clinical Endocrinology 88 114-122. (https://doi.org/10.1111/cen.13473)

Zhao L, Dias-Santagata D, Sadow PM \& Faquin WC 2017 Cytological, molecular, and clinical features of noninvasive follicular thyroid neoplasm with papillary-like nuclear features versus invasive forms of follicular variant of papillary thyroid carcinoma. Cancer Cytopathology 125 323-331. (https://doi.org/10.1002/cncy.21839)

Received in final form 21 February 2019 Accepted 7 March 2019 (c) 2019 Society for Endocrinology Published by Bioscientifica Ltd. Printed in Great Britain 